\title{
Analysis of Plastic Zone and Pressure Variance Features of Surrounding Rock of High-Altitude Macker Tunnel: A Case Study in Jiangluling Macker Tunnel in Qinghai
}

\author{
Xiaojun Ma, ${ }^{1}$ Hongyan Guo $\mathbb{D}^{2,3}$ Juyi Hu, ${ }^{2}$ Shuang Cai $\mathbb{D}^{2},{ }^{2}$ Liang Cheng, \\ and Danfeng Zhang ${ }^{1}$ \\ ${ }^{1}$ Qinghai Communications Construction Management Co. Ltd., Xining, Qinghai, 810003, China \\ ${ }^{2}$ China Merchants Chongqing Communications Technology Research \& Design Institute Co. Ltd., Chongqing 400067, China \\ ${ }^{3}$ Chongqing University, Chongqing 400044, China
}

Correspondence should be addressed to Hongyan Guo; 717692502@qq.com and Shuang Cai; caishuang@cmhk.com

Received 16 September 2021; Accepted 13 October 2021; Published 21 October 2021

Academic Editor: Guoming Liu

Copyright (c) 2021 Xiaojun Ma et al. This is an open access article distributed under the Creative Commons Attribution License, which permits unrestricted use, distribution, and reproduction in any medium, provided the original work is properly cited.

Due to the special mechanical properties of macker rock, problems may be caused easily if the pressure of the surrounding rock calculated from the standard empirical equation is used in the structural design of tunnel support, such as obviously insufficient bearing capacity of the support structure, large deformation, and collapse. Taking the Jiangluling Macker Tunnel in GongheYushu Highway as an example, the distribution pattern of plastic zone of the surrounding rock and the calculation method and reasonable values of pressure of the surrounding rock are studied in this paper, by means of theoretical analysis, numerical computation, and field measurement data. The results show that the elastic-plastic analysis method is suitable for the pressure of the surrounding rock of macker tunnel. The influence radius of the plastic zone of the surrounding rock can be $32 \mathrm{~m}$, and the lateral pressure of the surrounding rock of the tunnel is equivalent to the vertical pressure. In the absence of test conditions and measured data, the pressure of the surrounding rock can be approximately $0.83 \mathrm{MPa}$ for the purpose of design of tunnel support structure. This conclusion provides technical support for projects in similar conditions.

\section{Introduction}

In China's Western Development Program, the buildup of a convenient transportation system is the necessity for economic development and social progress in the western region and the improvement of land traffic network also requires expansion of transportation infrastructure into naturally severe, high-latitude, and high-altitude cold regions. With the rise of construction of railways and highways in Tibetan region, increasing attention from the engineering community has been paid to the construction technology for tunnels in high-altitude and cold areas. Jiangluling Tunnel in Gonghe-Yushu Highway is a typical high-altitude macker tunnel in cold region. Due to lack of understanding of the mechanical properties of the surrounding rock of high-altitude macker [1], the distribution pattern of the plastic zone of the surrounding rock $[2,3]$, the variation law of the pressure of the surrounding rock, and the reasonable values of the pressure of the surrounding rock are unclear when the tunnel support structure is designed, thus resulting in engineering problems occurring in the process of tunnel construction, such as large deformation, extrusion and collapse of the surrounding rock, uplift of tunnel bottom, cracking of support structure, and deformation and damage of lining.

The majority of domestic studies on macker tunnel focus on mechanical properties, deformation rules and deformation mechanism of the surrounding rock [4], instability failure mechanism, and engineering treatment measures [5]. For example, $\mathrm{Na}$ Qicai et al. conducted indoor remodeling of rock sample according to natural density and water content of the rock and obtained mechanical parameters of rock by means of indoor direct shear compression test, value range of elastic modulus through conversion of modulus of compression, and 
accurate value of elastic modulus with the help of numerical inverse analysis [6]. Based on measured data regarding construction monitoring of the surrounding rock of the Shazizhi Macker Tunnel in western Zhengzhou, Wang Cheng et al. analyzed the variances of the surrounding rock of a macker tunnel in layered structure over time and proposed corresponding variance equations [7]. Through statistical analysis of field measured data, working face sketching, and application of theories about engineering geology and structural mechanics, Tian Siming analyzed the deformation and damage mechanism of high-geostress macker, discussed the impact of bedded rock and soft rock strata on the stability of tunnel surrounding rock, and revealed the mechanical mechanism of deformation and damage of high-geostress macker [8]. Teng Junyang et al. found through their study that heaving floor of a macker tunnel is caused by a combination of factors including low intensity of tunnel surrounding rock [9], softening and hydraulic pressure effect of groundwater on the surrounding rock, and rheology of macker [10]. However, there is little research on reasonable values of pressure of the surrounding rock of the macker tunnel [11,12], which is very disadvantageous to engineering design.

Therefore, starting from the actual situation of the construction of Jiangluling Tunnel in Gonghe-Yushu Highway, this paper studies the values of pressure of the surrounding rock of Jiangluling Macker Tunnel, and it is intended to provide a basis and technical support for the design of similar projects.

\section{Project Overview}

Jiangluling Tunnel, as a typical high-altitude permafrost highway tunnel in cold region, is located in the GongheYushu (Jiegu) Highway along National Route 214 and its entrance and exit are more than $4,300 \mathrm{~m}$ above sea level. The left line of the tunnel is $2925 \mathrm{~m}$ long, and the right line is $2845 \mathrm{~m}$ long, as shown in Figure 1(a). Tunnel excavation revealed that the surrounding rock is mainly composed of green-gray and gray-black silty macker and slate interbedded with a small amount of thin-medium-thickness quartzite, crystalline limestone, and sand slate. Silty macker and slate, classified as soft rock, are in thin-very thin silty structure and have poor silty calcareous cementation performance, as shown in Figure 1(b). Their bedding surface is quite prone to cracking. They are easily softened in case of contact with water and are heavily influenced by weathering. Interstratigraphic folds and small compression faults are developed, join fissure is well developed, and rock mass is more fractured, fragmentary, and lamellar.

Due to extrusion of macker, after tunnel excavation and early support placement, daily average deformation rate stays at $10-30 \mathrm{~mm}$ and accumulative maximum deformation reaches $40-80 \mathrm{~cm}$. Moreover, such engineering problems as early support cracking, invasion limit, collapse of the surrounding rock on the working surface, inverted arch, heaving floor, and secondary lining cracking are accompanied, and these problems result in extremely heavy engineering risk, significant construction difficulty, and up to 6 years of the construction period.

\section{Methodology}

Now, the common test methods for the distribution range of plastic zone of the surrounding rock mainly include acoustic wave method, multipoint displacement meter method [7], seismic wave method, geological radar method, and advanced borehole camera technology [13, 14]. Finally, in combination with actual construction situation of Jiangluling Tunnel, the acoustic wave method and multipoint displacement meter method are used to test the broken rock zone of the surrounding rock and conducting contrastive analysis [15].

\subsection{Test of Plastic Zone of Surrounding Rock}

\subsubsection{Test Principle}

(1) Acoustic Wave Method. The acoustic wave method is a widely accepted and well-developed test method for broken rock zone of the surrounding rock and its feasibility has been proven by a large number of engineering practices. Its test principle is that acoustic wave travels in rock and its velocity will fall with the development of fracture in rock mass, the decrease in density, and the increase in acoustic impedance. On the contrary, if the rock mass has good integrity, heavy stress, and large density, the propagation velocity of the acoustic wave should also be significant, as shown in Figure 2. As a result, for the surrounding rocks of the same nature, high measured acoustic wave velocity indicates better integrity of the surrounding rock and low velocity indicates the presence of fissure in the surrounding rock and damage to the surrounding rock. An acoustic wave tester is used to measure the acoustic wave velocity values of rocks at different depths from the surface of the surrounding rock and depth and acoustic wave velocity curves are drawn. Then, the thickness of the broken rock zone of the surrounding rock in the lane under test is inferred according to related geological data.

(2) Multipoint Displacement Meter Method. Many multipoint displacement meters are generally used in the coal production process to obtain large sets of monitoring data, to study the stability of lane surrounding rock or the displacement inside the surrounding rock. Analysis of these sets of monitoring data can also bring us to the range of thickness of the broken rock zone of the surrounding rock. A multipoint displacement meter is used to measure the rock displacement variation at different depths in the surrounding rock. According to the curve of time-varying displacement measured by displacement meter, the convergence of rocks at different depths in the surrounding rock toward drift can be derived. The larger displacement variation with time indicates that the rock mass within the range of this position is fractured. Therefore, through analysis of the displacement and time variation of different points, the broken rock zone and the slightly disturbed zone can be identified, as shown in Figure 3. 


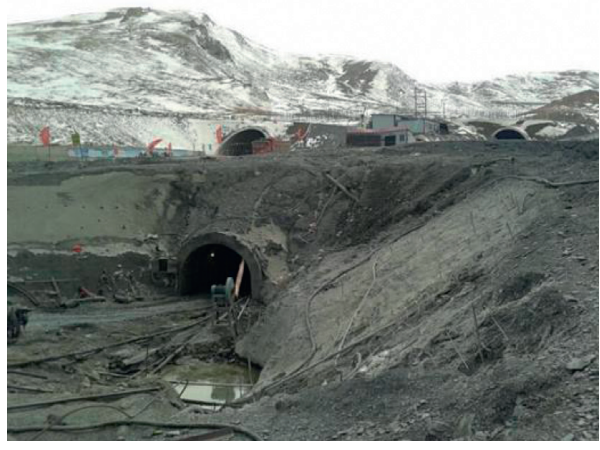

(a)

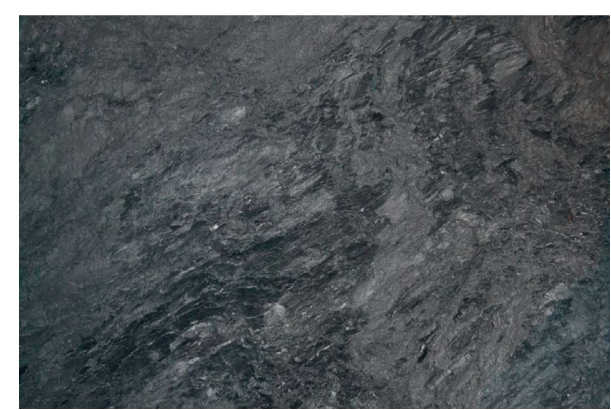

(b)

Figure 1: Jiangluling Tunnel. (a) Cross section of the tunnel entrance. (b) Photo of the surrounding rock at tunnel entrance face.

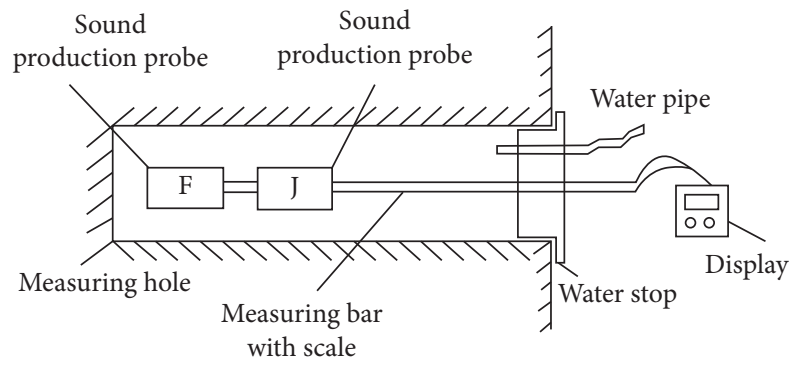

Figure 2: Principle of acoustic wave test.

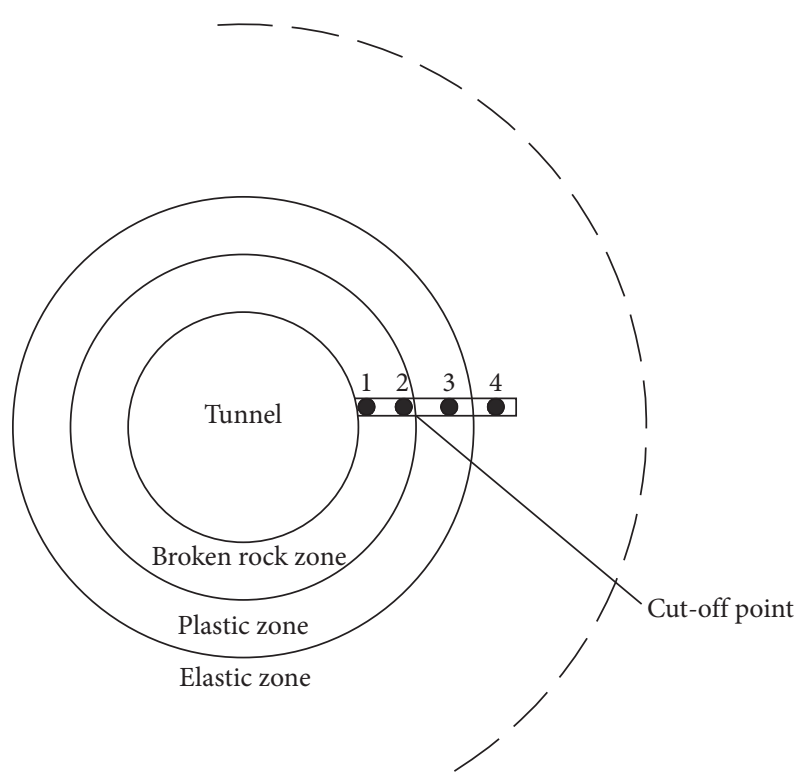

FIGURE 3: Test principle of multipoint displacement meter method.

3.1.2. Test Scheme. Six survey sections are arranged in Jiangluling Tunnel according to the on-site construction conditions and geological conditions of the surrounding rock, including two for left and right portals at the entrance and one for left and right portals at the exit, respectively, which are ZK330+875, ZK330+897, ZK331+625, YK330+847, YK330+855, and YK331 + 475 in turn. Because the vaults are not easy for irrigation and grouting, 4 measuring points are arranged on each section, which are left and right haunches and left and right side walls in turn, as shown in Figure 4(a).

Down-the-hole drilling is used at each measuring point, with a hole depth of 8-9 $\mathrm{m}$ and an aperture of $120 \mathrm{~mm}$, as shown in Figure 4(b). After drilling, the acoustic wave test (Figure 5) is adopted, and then the multipoint displacement meter (Figure 6) is embedded for long-term monitoring. By comparing and analyzing the test results of the two different methods, the distribution range of the plastic zone of the surrounding rock of the macker tunnel is obtained.

3.2. Stress Test of Surrounding Rock. The surrounding rock is tested by embedding a pressure cell between the steel support and the surrounding rock so that the contact pressure between the surrounding rock and the primary support is analyzed. Six survey sections are arranged according to the on-site construction conditions and geological conditions of the surrounding rock, including two for left and right portals at the entrance and one for left and right portals at the exit, respectively, which are ZK330 + 875, ZK330+897, ZK331 + 625, YK330+847, YK330+855, and YK331 + 475 in turn. There are 5 measuring points on each section, namely, vault, left and right haunches, and left and right side walls, as shown in Figure 7.

\section{Results and Discussions}

\subsection{Test Results and Discussion on Plastic Zone of Surrounding Rock}

4.1.1. Analysis of Results from Acoustic Wave Test. The acoustic wave method is an instant test, which can only give the loosening condition of the surrounding rock in the current test state. By analyzing the variation pattern of acoustic wave propagation velocity in the surrounding rock at different depths after primary supporting, the influence range of the surrounding rock and the distribution range of the plastic zone of the surrounding rock can be determined. Because water column coupling is required between the probe and surrounding rock during acoustic wave test, it is easy for holes at measuring points 2 and 3 to collapse, and it is difficult to effectively block water. Therefore, only 


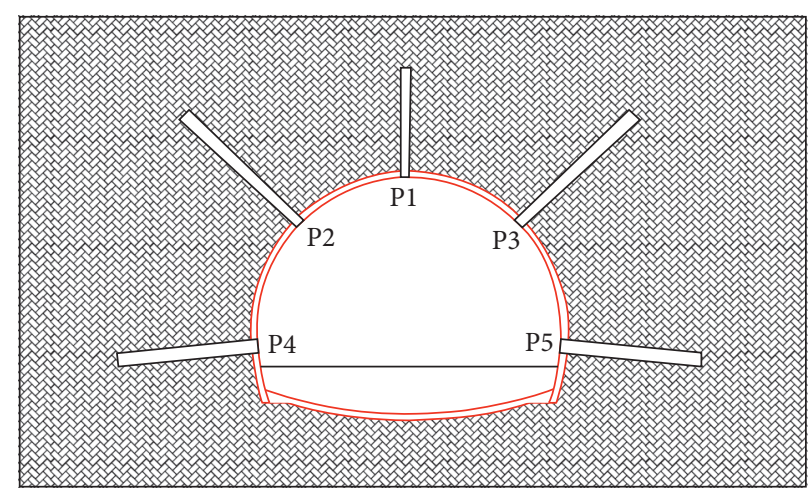

(a)

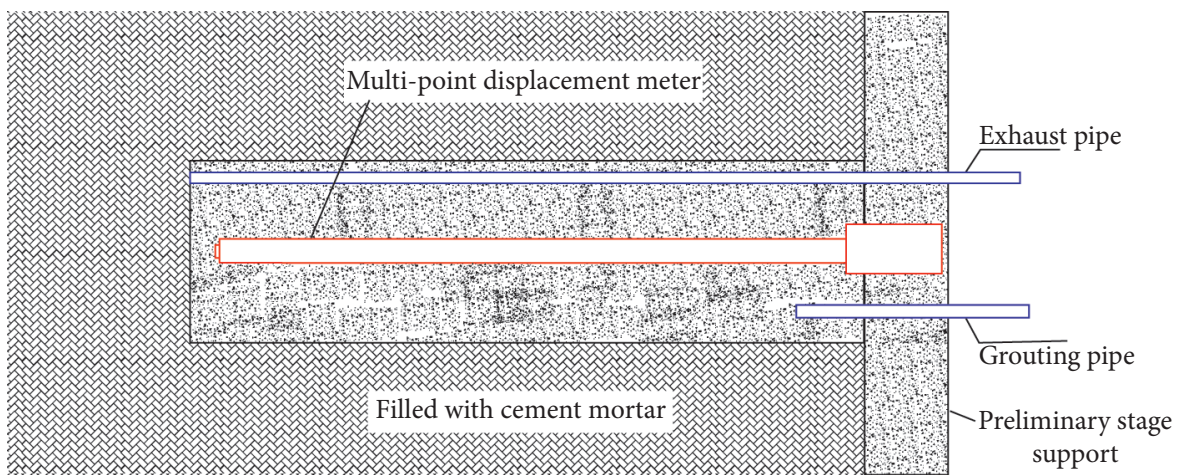

(b)

FIGURE 4: Layout of section measuring points and installation method of multipoint displacement meter. (a) Layout of measuring points, the borehole depth $L=8.0 \mathrm{~m}$ and aperture $\Phi 70 \mathrm{~mm}$. (b) Multipoint displacement meter installation diagram, the borehole depth $L=8.0-9.0 \mathrm{~m}$ and aperture $\Phi 120 \mathrm{~mm}$.

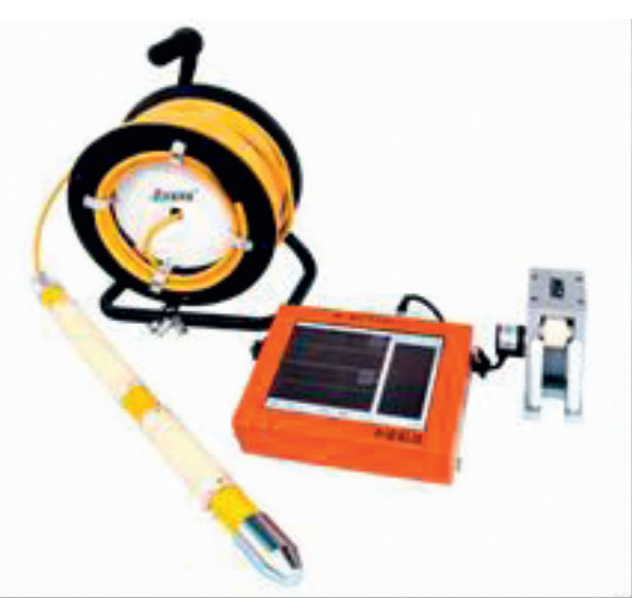

FIGURE 5: YL-LCT broken rock zone tester (Shanghai Y-Link Engineering and Technology Co., Ltd., China).

measuring points 1 and 4 are subjected to acoustic wave test. As the test results on the left and right sides are symmetrical and similar, the test results on one side (as shown in Figure 8) are given below to determine the distribution range of the plastic zone of the surrounding rock.

It can be derived from Figure 8 that, within the range of $0-8 \mathrm{~m}$ from the primary supporting free face of the macker tunnel, the acoustic wave propagation velocity

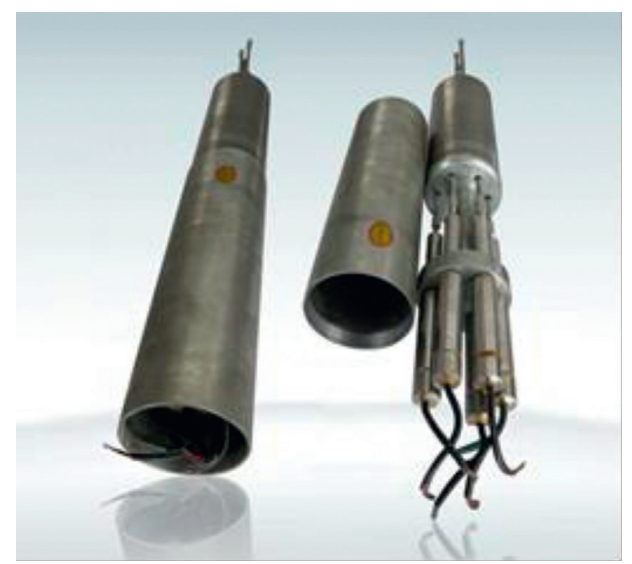

FIgURE 6: Multipoint (4-point) displacement meter (Shandong Heng'an Electronic Technology Co., Ltd., China).

was rather low, and the wave velocity error fell between 0.8 and $1.6 \mathrm{~km} / \mathrm{s}$. The figure also shows a trend of slow increase, which indicates that, with the deepening of the tunnel depth, the density of the surrounding rock increases, and the degree of the surrounding rock affected by excavation decreases gradually. However, the wave velocity error did not change suddenly but increased slowly, and the wave velocity error in the deep layer was slightly higher than that in the shallow layer, which 


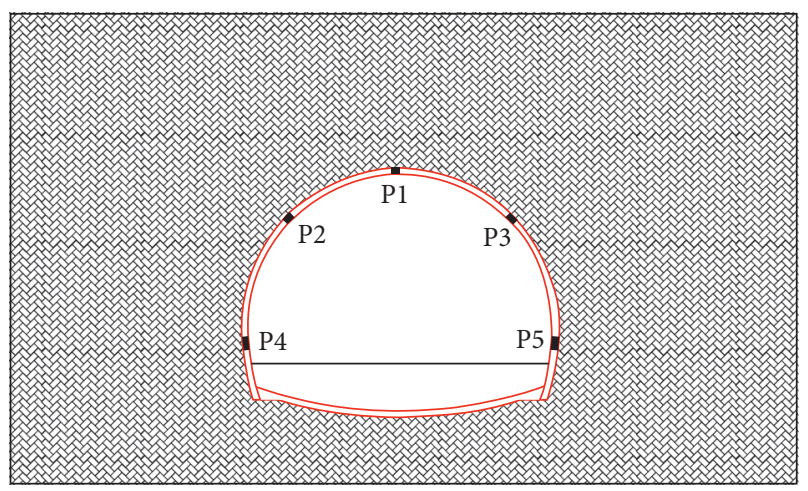

FIGURE 7: Layout of stress measuring points of the surrounding rock, the borehole depth $L=8.0 \mathrm{~m}$ and aperture $\Phi 70 \mathrm{~mm}$.

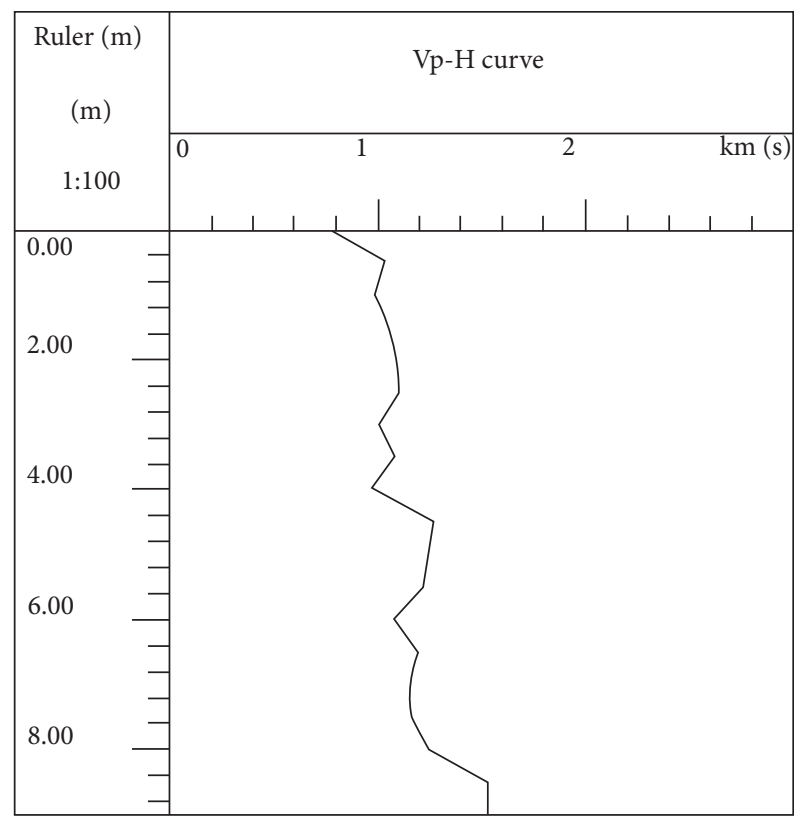

FIGURE 8: Variation pattern of wave velocity error with depth of measuring point.

means that the surrounding rock of the macker tunnel was greatly affected within the test depth $(8 \mathrm{~m})$, where plastic deformation occurred; that is, the distribution range of plastic zone of the surrounding rock of the macker tunnel was not less than $8 \mathrm{~m}$.

\subsubsection{Analysis of Test Results from Multipoint Displacement} Meter Method. The multipoint displacement method is to use a multipoint displacement meter to measure the rock displacement variation at different depths in the surrounding rock. According to the curve of displacement measured by displacement meter, the convergence of rocks at different depths in the surrounding rock toward drift can be derived. The larger displacement variation with time indicates that the rock mass within this position is cracked. Therefore, through analysis of the displacement and time variation of different points, the broken rock zone and the slightly disturbed zone can be identified. Four-point displacement meters with a length of $8.0 \mathrm{~m}$ are embedded at the test points of each test section on-site for long-term monitoring. In order to facilitate comparative analysis, the monitoring results of the same test point are also taken for analysis, as shown in Figure 9.

As shown in Figure 4, the displacement of the deep part of the surrounding rock decreases with the increase of depth. However, after tunnel excavation, the axial displacements of four measuring points $(2 \mathrm{~m}, 4 \mathrm{~m}, 6 \mathrm{~m}$, and $8 \mathrm{~m}$ ) in the surrounding rock relative to the free face of the surrounding rock are very small. The monitoring data show that the deformation of the surrounding rock reaches $60-80 \mathrm{~cm}$ after tunnel excavation, which means that, after tunnel excavation, the relative displacement between the surrounding rock and surface within $8 \mathrm{~m}$ around the tunnel is close to 0 ; that is, the surrounding rock shrinks inward at the same time within $8 \mathrm{~m}$ around the tunnel. Then, it shows that the plastic zone distribution range of the Jiangluling Macker Tunnel is larger than $8 \mathrm{~m}$, which is consistent with the results measured with the acoustic wave method.

4.1.3. Discussion. According to the results of the two test methods, the plastic zone radius of the surrounding rock in the Jiangluling Macker Tunnel is greater than $8 \mathrm{~m}$, which is demonstrated by numerical analysis as follows. Calculation and analysis are conducted with FLAC3D software. Numerical calculation and analysis mode is shown in Figure 10 and mechanical parameters regarding the surrounding rock are obtained through laboratory experiment, as shown in Table 1.

As shown in Figure 11(a), after the excavation of the macker tunnel, the plastic zone of the surrounding rock is distributed in $X$ shape with a large reverse distribution range, and the yield range of the surrounding rock is 14-38 m. After tunnel excavation, the radius of the area where the shear strain of the surrounding rock is greater than 0.01 is $15-32 \mathrm{~m}$. Based on the two analysis results, the distribution range of the plastic zone of the surrounding rock in the Jiangluling Macker Tunnel is $15 \mathrm{~m}$ in a horizontal direction and $32 \mathrm{~m}$ in a numerical direction (Figure 11(b)). Therefore, during the calculation of the pressure of the surrounding rock in the macker tunnel, the influence radius of the plastic zone of the surrounding rock can be $32 \mathrm{~m}$, and then the empirical formula or theoretical formula can be used for calculation.

\subsection{Surrounding Rock Stress Test Results and Discussion}

4.2.1. Test Results. The test results of typical sections are extracted to draw the law of variation in pressure of the surrounding rock with time and the cross-sectional drawing of the surrounding rock pressure spatial distribution, as shown in Figures 12 and 13, respectively.

The results of the test and analysis on the pressure of the surrounding rock in the Jiangluling Tunnel show the following: 


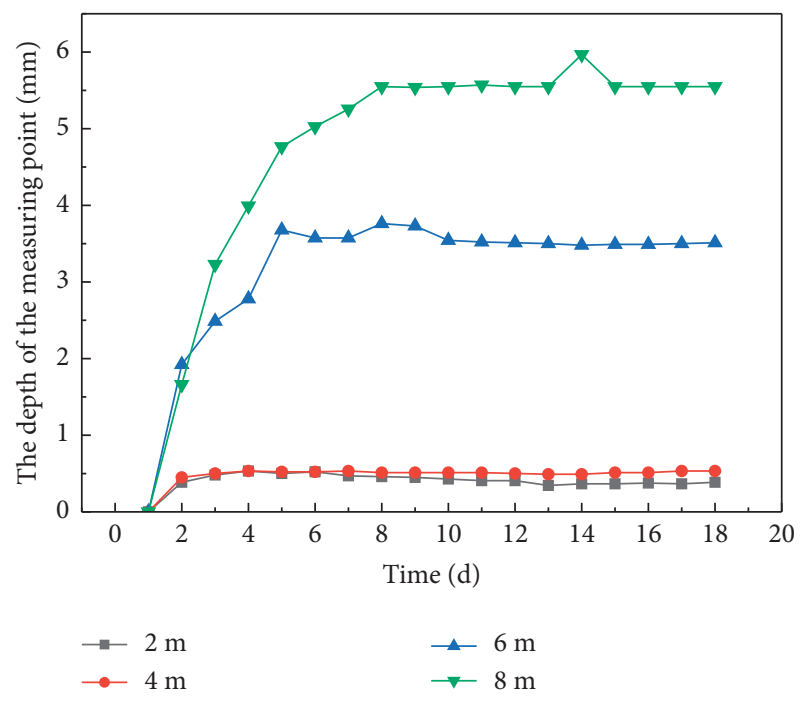

FIGURE 9: Law of variation in the surrounding rock displacement with time at different depths.

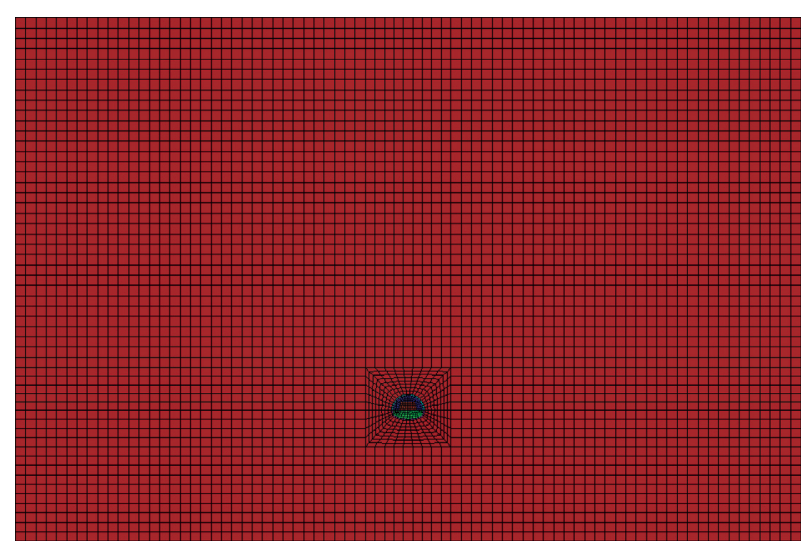

FIGURE 10: Numerical calculation and analysis model.

TABLE 1: Mechanical parameters value of the surrounding rock.

\begin{tabular}{lcccc}
\hline S. no. & Parameter name & Symbol & Unit & Value \\
\hline 1 & Density & $\rho$ & $\mathrm{kg} / \mathrm{m}^{3}$ & 2593 \\
2 & Water content & $\omega$ & $\%$ & 3.78 \\
3 & Elastic modulus & $\mathrm{E}$ & $\mathrm{GPa}$ & 0.201 \\
4 & Poisson ratio & $\mathrm{u}$ & - & 0.28 \\
5 & Cohesion & $\mathrm{c}$ & $\mathrm{KPa}$ & 88.94 \\
6 & Angle of internal friction & $\varphi$ & ${ }^{\circ}$ & 29.46 \\
\hline
\end{tabular}

(1) As shown in Figure 12, the law of variation in pressure of the surrounding rock in the macker tunnel can be divided into three stages: rapid growth, slow growth, and stabilization, which correspond to three nodes of the surrounding rock excavation, inverted arch construction, and secondary lining construction in turn.

(2) As shown in Figure 13, the lateral pressure of the macker tunnel is basically equivalent to the vertical pressure, and the pressure of the surrounding rock is evenly distributed around the tunnel. The pressure of the surrounding rock is $0.4-0.8 \mathrm{MPa}$, and the lateral pressure coefficient is approximately 1.0.

4.2.2. Discussion. At present, the study of tunnel surrounding rock is mainly divided into two research directions of empirical formula method and theoretical calculation method [16], of which the empirical formula method is a widely used and mature method to determine the pressure of the surrounding rock [10]. It is a summary of experience based on numerous practical engineering data and put forward according to different surrounding rock grades; it is convenient for engineers and technicians to obtain the magnitude and distribution mode of the pressure of the surrounding rock conveniently and quickly. The empirical formula method can be roughly divided into two categories, of which the first category is based on Platts theory, Terzaghi theory, and the form of $q=\gamma h$ Chinese standard method [17] with difference only lying in the difference of equivalent thickness $h$. This category, with a single influencing factor, is easy to use, but the calculated results are quite different from the actual situation. The second category is the index type formula based on $Q$ or RMR classification system. Taking into consideration the influence of many factors, this type of formula has great progress compared with the former $[2,18]$. However, due to the consideration of more indexes, the selection of these indexes has great subjectivity. As one of the methods to determine the pressure of the surrounding rock, the theoretical calculation is developed based on elastic-plastic theory and computer technology, including the theoretical formula method and numerical calculation method [19]. The theoretical formula method is mainly based on the circular tunnel model, including several elliptical tunnels, most of which are deep-buried traffic tunnels or circular roadways with high geostress, strong compression, and large deformation. The representative theoretical formulas mainly include Caquot plastic zone broken-rock pressure formula [20] (formula (1)), Fenner formula [13] (2), modified Fenner formula [21] (3), and Kastner formula.

$$
p=c \cdot \cot \varphi\left[\left(\frac{r_{0}}{R}\right)^{\xi-1}-1\right]+\frac{r \cdot r_{0}}{\xi-2}\left[1-\left(\frac{r_{0}}{R}\right)^{\xi-2}\right]
$$

where $p$ is the broken-rock pressure of plastic zone: $c$ is the cohesive force of rock mass; $\varphi$ is the angle of internal friction of rock mass; $R$ is the radius of plastic ring; $\xi$ is the plasticity coefficient; $r_{0}$ is the cavern radius; $\gamma$ is the bulk density of rock mass.

$$
\begin{aligned}
& p=\left[c \cdot \cot \varphi+p_{0}(1-\sin \varphi)\right]\left(\frac{r_{0}}{R}\right)^{2 \sin \varphi / 1-\sin \varphi}-\cot \varphi, \\
& p=\left(c \cdot \cot \varphi+p_{0}\right)(1-\sin \varphi)\left(\frac{r_{0}}{R}\right)^{2 \sin \varphi / 1-\sin \varphi}-c \cdot \cot \varphi .
\end{aligned}
$$

In formulas (2) and (3), $p$ is the deformation pressure of the surrounding rock acting on structure; $p_{0}$ is the original geostress; other parameters are the same as above. 


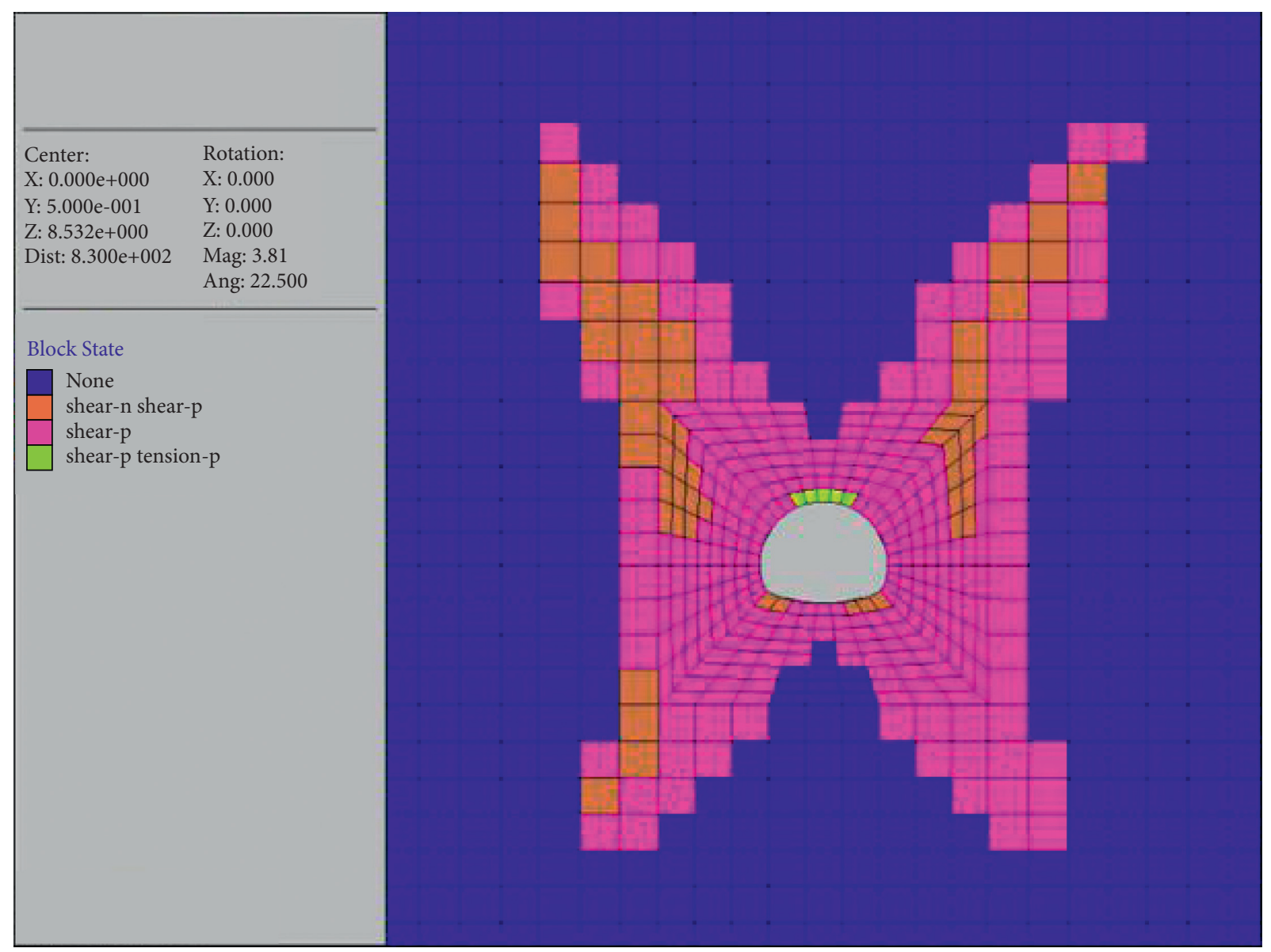

(a)

Figure 11: Continued. 


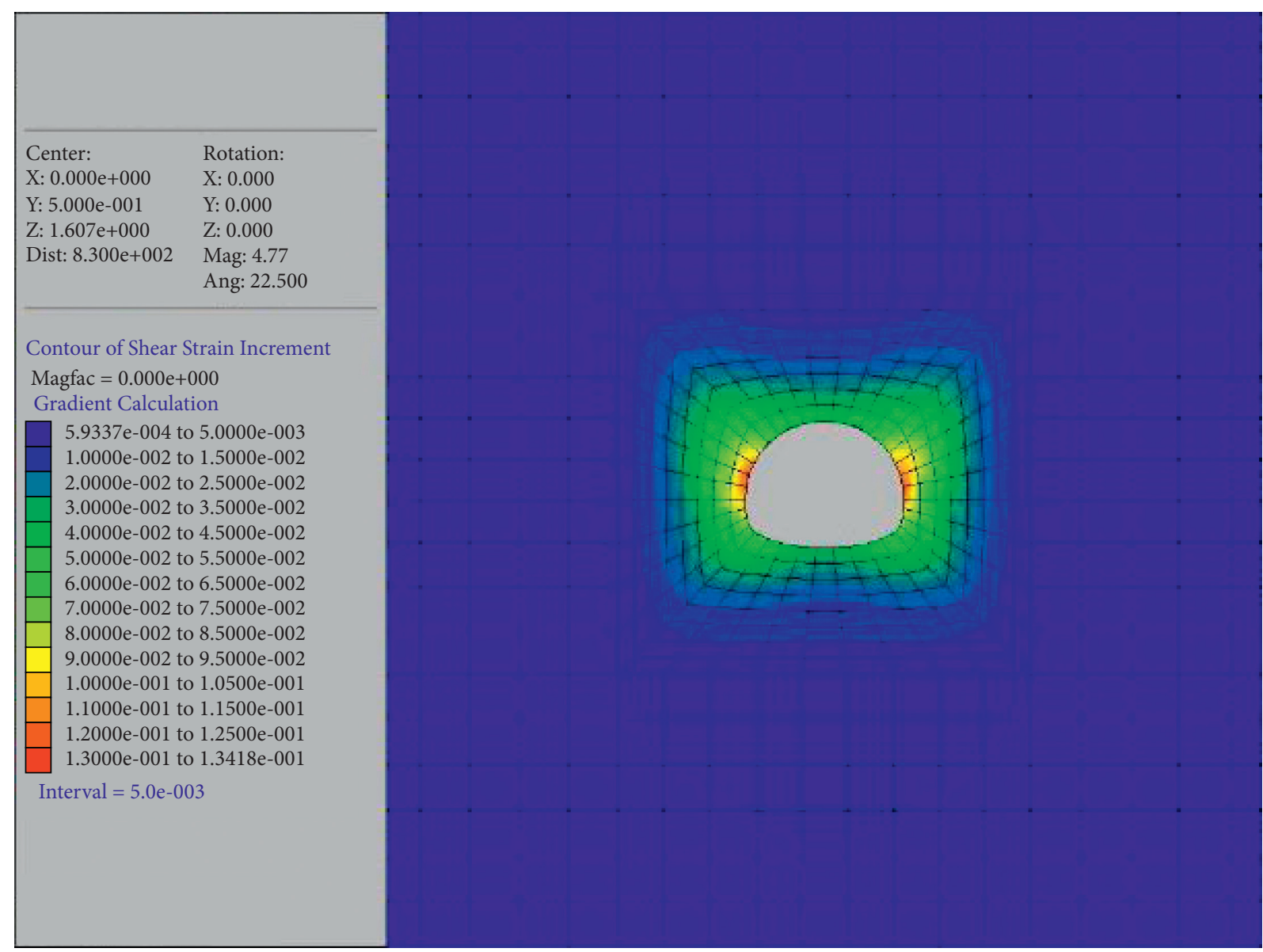

(b)

FIGURE 11: Numerical analysis results of the plastic zone radius of the surrounding rock in Jiangluling Macker Tunnel. (a) Distribution diagram of the plastic zone of the surrounding rock. (b) Distribution diagram of shear strain of the surrounding rock.

From the perspective of theoretical research results of the pressure of the surrounding rock, the key index of deepburied tunnel affecting the pressure of the surrounding rock is equivalent to loose layer thickness or plastic zone radius of surrounding rock. It is more reasonable to study the pressure of the surrounding rock in a macker tunnel as a kind of strong-extrusion and large-deformation tunnel by the elastic-plastic analysis method. The key of the study is to analyze the plastic zone of the surrounding rock in a macker tunnel and obtain a reasonable radius of the plastic zone of the surrounding rock.

The monitoring data of some typical large-deformation tunnels in China have been investigated. The monitoring results of the pressure of the surrounding rock are statistically compared and analyzed. The selected tunnels mainly include Baojiashan Tunnel, Wushaoling Tunnel, Xiangshan Tunnel, Humaling Tunnel, and Qingshashan Tunnel. The above 5 tunnels have largedeformation problems during construction, and the pressure of the surrounding rock in corresponding sections is monitored. The test and analysis results of the pressure of the surrounding rock in each tunnel are shown in Table 2 .
The comparative analysis results of the pressure of the surrounding rock in the above five tunnels show the following:

(1) The above tunnels are all surrounding rocks of Class $\mathrm{V}$ or Class VI, with large deformation of soft rock existing in the tunnel construction process, which is similar to the Jiangluling Macker Tunnel with certain reference significance in the test results of the pressure of the surrounding rock. As far as lithology is concerned, the lithology of the Wushaoling Tunnel and Qingshashan Tunnel is closer to that of the Jiangluling Tunnel, with a greater reference value [22].

(2) The pressure of the surrounding rock in the tunnel is relatively high, ranging from $0.4 \mathrm{MPa}$ to 1.1 $\mathrm{MPa}$, which is higher than the calculation result of the empirical formula in the code. At the same time, the lateral pressure and vertical pressure of the surrounding rock of the tunnel are almost equal, and the lateral pressure coefficient is close to 1.0 , which is quite different from that of the relevant code [23]. 


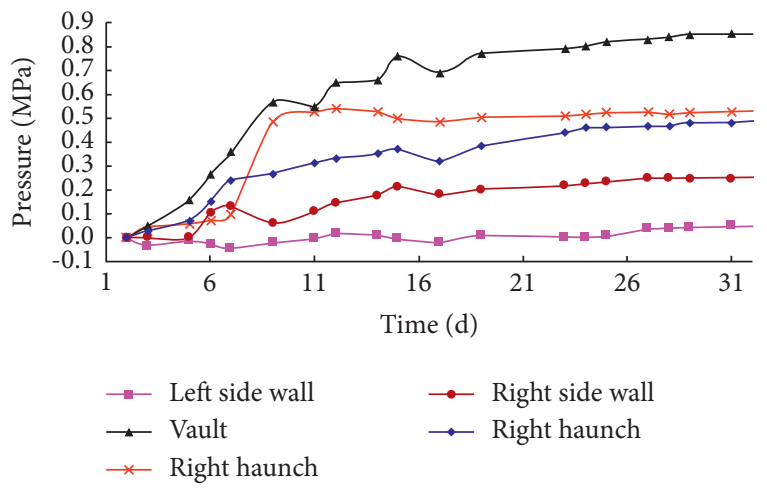

FIGURE 12: Law of variation in pressure of the surrounding rock in typical cross-section tunnel with time.

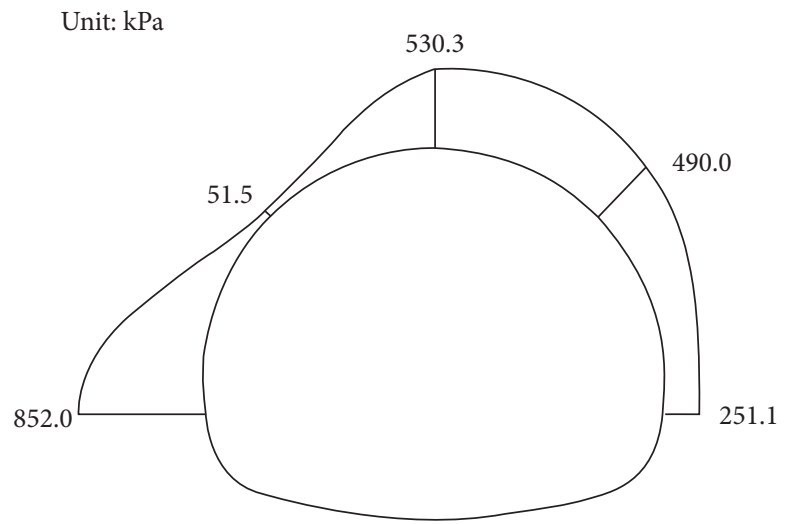

FIGURE 13: Cross-sectional diagram of the spatial distribution of pressure of the surrounding rock in a typical cross-section tunnel.

TABLE 2: Results of test on pressure of the surrounding rock in similar projects.

\begin{tabular}{|c|c|c|c|c|}
\hline $\begin{array}{l}\text { S. } \\
\text { no. }\end{array}$ & Tunnel name & $\begin{array}{c}\text { Tunnel } \\
\text { category }\end{array}$ & $\begin{array}{c}\text { Characteristics of rock mass in pressure test section } \\
\text { of the surrounding rock }\end{array}$ & $\begin{array}{l}\text { Maximum pressure of the surrounding rock } \\
(\mathrm{MPa}) \text { (location) }\end{array}$ \\
\hline 1 & $\begin{array}{c}\text { Baojiashan } \\
\text { Tunnel }\end{array}$ & $\begin{array}{l}\text { Highway } \\
\text { tunnel }\end{array}$ & Weak and broken rock mass & 0.44 (haunch) \\
\hline 2 & $\begin{array}{l}\text { Wushaoling } \\
\text { Tunnel }\end{array}$ & $\begin{array}{l}\text { Railway } \\
\text { tunnel }\end{array}$ & Fault crushing zone, phyllite & 0.60 (vault) \\
\hline 3 & $\begin{array}{c}\text { Xiangshan } \\
\text { Tunnel }\end{array}$ & $\begin{array}{l}\text { Railway } \\
\text { tunnel }\end{array}$ & Large deformation of soft rock & 0.41 (vault) \\
\hline 4 & Humaling Tunnel & $\begin{array}{l}\text { Highway } \\
\text { tunnel }\end{array}$ & Water-rich silt-fine sandstone & 0.53 (sidewall) \\
\hline 5 & $\begin{array}{l}\text { Qingshashan } \\
\text { Tunnel }\end{array}$ & $\begin{array}{l}\text { Highway } \\
\text { tunnel }\end{array}$ & Regional fault, phyllite & 1.06 (sidewall) \\
\hline
\end{tabular}

From three aspects of empirical formula, theoretical analysis, and field measurement, the pressure of the surrounding rock in the Jiangluling Macker Tunnel has been studied. Now, the results of the 3 methods are compared and analyzed. For the empirical formula method, the Code for Design of Highway (Railway) Tunnel and the Specification for Design of Hydraulic Tunnel are adopted to calculate in accordance with the surrounding rock of Class $\mathrm{V}$, with the tunnel excavation width of $B=13.0 \mathrm{~m}$, the tunnel excavation height of $H=10.5 \mathrm{~m}$, and the lateral pressure coefficient of 0.389. For the theoretical formula, the Caquot plastic zone broken-rock pressure formula is adopted, with the plastic zone radius of $32 \mathrm{~m}$ and the comparative analysis results shown in Table 3.

As shown in Table 3, the results calculated according to the empirical formula recommended by the code are obviously small for the macker tunnel, and those calculated according to the theoretical formula method are close to those of field measurement, which are slightly larger than the field measurement values. In other words, the pressure of the surrounding rock in the Jiangluling Macker Tunnel can be obtained by the Caquot plastic zone broken-rock pressure formula or field measurement. Under the condition where there are no accurate mechanical parameters of the 
TABLE 3: Results of comprehensive comparative analysis.

\begin{tabular}{lcccc}
\hline $\begin{array}{l}\text { Pressure of the surrounding } \\
\text { rock }\end{array}$ & $\begin{array}{c}\text { Empirical formula method } \\
\text { Code for design of } \\
\text { highway (railway) tunnel }\end{array}$ & $\begin{array}{c}\text { Specification for design of } \\
\text { hydraulic tunnel }\end{array}$ & $\begin{array}{c}\text { Theoretical formula method } \\
\text { Caquot plastic zone broken- } \\
\text { rock pressure formula }\end{array}$ \\
\hline Vertical pressure $(\mathrm{MPa})$ & 0.31 & 0.10 & 0.83 & 0.703 \\
Horizontal pressure $(\mathrm{MPa})$ & 0.13 & 0.03 & 0.83 & 0.625 \\
\hline
\end{tabular}

surrounding rock and the field test conditions are not available, the vertical pressure and pressure of the surrounding rock in the macker tunnel can be $0.83 \mathrm{MPa}$, and the support structure design can be carried out.

\section{Conclusion}

(1) For the macker tunnel, one of the tunnels with strong extrusion and large deformation, the elastic-plastic analysis method is more reasonable to study the pressure of the surrounding rock, and the reasonable radius of the plastic zone of the surrounding rock is the key to study with the theoretical formula method.

(2) After the excavation of the macker tunnel, the plastic zone of the surrounding rock is distributed in $X$ shape with a wide distribution range, and the radius of the area where the shear strain of the surrounding rock is greater than 0.01 is $15-32 \mathrm{~m}$. Therefore, the influence radius of the plastic zone of the surrounding rock can be $32 \mathrm{~m}$ when calculating the pressure of the surrounding rock in the macker tunnel.

(3) The variation law of pressure of the surrounding rock in a macker tunnel can be divided into three stages of rapid growth, slow growth, and stabilization. The lateral pressure is basically equivalent to the vertical pressure of the surrounding rock and is uniformly distributed.

(4) The pressure of the surrounding rock in the Jiangluling Macker Tunnel is recommended to be obtained by the Caquot plastic zone broken-rock pressure formula or field measurement. The vertical pressure and pressure of the surrounding rock in the macker tunnel can be $0.83 \mathrm{MPa}$ if there are no accurate mechanical parameters of the surrounding rock and the field test conditions are not available.

(5) On-site testing and numerical analysis methods are used in this paper to provide the values of pressure of the surrounding rock of a high-altitude macker highway tunnel. However, since not all actual engineering conditions are covered, these methods are now merely applicable to tunnels of this project. They can be used as a reference for similar projects and the subsequent projects can be further guided through verification and optimization of a large number of similar projects.

\section{Data Availability}

The data used to support the findings of this study are available from the corresponding author upon request.

\section{Conflicts of Interest}

The authors declare that they have no conflicts of interest.

\section{Acknowledgments}

This paper was jointly funded by the Qinghai Transportation Science and Technology Project (no. 2020-01) and the Science and Technology Project of the Transportation Department of Guizhou Province (no. 2020-122-031).

\section{References}

[1] J. Teng and J. Tang, "Mechanism analysis of floor heave in layered carbonaceous shale tunnel," Journal of Railway Science and Engineering, vol. 14, no. 1, pp. 110-116, 2017.

[2] X. Mo, "Determination of the design pressure and stand-up time for primary support," China Civil Engineering Journal, vol. 35, no. 1, pp. 62-67, 2002.

[3] W. Hui, Z. Peng-qiang, Z. Wen-juan, and T. Hong-ming, "Application of a combined supporting technology with U-shaped steel support and anchor-grouting to surrounding soft rock reinforcement in roadway," Journal of Central South University, vol. 25, pp. 1240-1250, 2018.

[4] L. Song, Y. Zhang, and M. Yu, "Unified solution for elastoplastic analysis of pressure tunnel," Engineering Mechanics, vol. 15, no. 4, pp. 57-61, 1998.

[5] H. Feng, C. Cw, C. Baj, D. Yh, D. Ng, and E. Wg, "Instability mechanism of shallow tunnel in soft rock subjected to surcharge loads," Tunnelling and Underground Space Technology, vol. 99, Article ID 103350, 2020.

[6] Q. Na, H. Guo, J. Hu, and S. Cai, "Surrounding rock mechanical parameters test and back analysis of carbonaceous shale tunnel," Chinese Journal of Underground Space and Engineering, vol. 12, no. S2, pp. 504-509, 2016.

[7] L. Li and Z. Tan, "Characteristic and mechanism research for large deformation problem in squeezing-shattered soft rock tunnel," Chinese Journal of Rock Mechanics and Engineering, vol. 37, pp. 3593-3603, 2018.

[8] C. Wang, M. Ding, and L. I. Qiang, "Study on deformation laws of carbonaceous shale tunnel in western hubei province," Chinese Journal of Underground Space and Engineering, vol. 3, no. S2, pp. 1442-1444, 2007.

[9] Z. J. Chen, "The mechanical problems for the long-term stability of underground galleries," Chinese Journal of Rock Mechanics and Engineering, vol. 1, no. 1, pp. 1-20, 1982.

[10] G. Liu, Y. Xiao, and J. Zhu, "Overview on theoretical calculation method of broken rock zone," Journal of China Coal Society, vol. 46, no. 1, pp. 46-56, 2021.

[11] W. Fan, Y. M. Hong, Y. W. Shi, and P. Sun, "The unified solution of the plastic relaxed pressures computing of surrounding rockmassess," Journal of Xi'an Engineering University, vol. 25, no. 1, pp. 33-36, 2003.

[12] J. Liu, C. Xie, and J. Rao, "Calculation model and influencing factors of surrounding rock loosening pressure for tunnel in 
fold zone," Advances in Civil Engineering, vol. 2021, no. 1, pp. 1-15, Article ID 6678511, 2021.

[13] P. Li, F. Wang, L. Fan, H. Wang, and G. Ma, "Analytical scrutiny of loosening pressure on deep twin-tunnels in rock formations," Tunnelling and Underground Space Technology, vol. 83, no. JAN, pp. 373-380, 2019.

[14] Y. X. Song, X. Y. Jia, and Y. Q. Zhu, "Study on vertical earth pressure calculation of metro tunnel," Rock and Soil Mechanics, vol. 28, no. 10, pp. 2240-2244, 2007.

[15] X. U. Kun, Z. J. Wang, M. Xiang-Lei, and C. S. Sun, "Research on detection technology for deep tunnel surrounding rock loose circle and numerical simulation analysis," Rock and Soil Mechanics, vol. 34, pp. 464-470, 2013.

[16] S. Alija, J. Torrijo, and M. Quinta Ferreira, "Geological engineering problems associated with tunnel construction in karst rock masses: the case of Gavarres tunnel (Spain)," Engineering geology amsterdam, vol. 157, pp. 103-111, 2013.

[17] S. Tian, "Deformation mechanism of black batt with high stress in Baozhen tunnel," Journal of Beijing Jiaotong University, vol. 37, no. 1, pp. 21-26, 2013.

[18] F. Huang, H. H. Zhu, Q. S. Li, and E. P. Li, "Field detection and theoretic analysis of loose circle of rock mass surrounding tunnel," Rock and Soil Mechanics, vol. 37, no. S1, pp. 145-150, 2016.

[19] Z. Wang, Z. Liu, W. Ma, S. Shi, and L. Bu, "Calculation method of underground cavern loosening pressure based on limit analysis using Upper-Bound theory and its engineering application[J]," Mathematical Problems in Engineering, vol. 2020, pp. 1-18, Article ID 5096931, 2020.

[20] M. Ahmed and M. Iskander, "Evaluation of tunnel face stability by transparent soil models," Tunnelling and underground space technology incorporating trenchless technology research, vol. 27, no. 1, pp. 101-110, 2015.

[21] Q. Zeng, E. Wang, and S. Wang, "Comparison between plastic radius around a circular opening derived from Hoek-Brown failure criterion and calculated through modified fenner formula," Journal of Shenyang Jianzhu University(Natural Science), vol. 24, no. 6, pp. 933-938, 2008.

[22] M. Cai, P. K. Kaiser, H. Morioka et al., "FLAC/PFC coupled numerical simulation of AE in large-scale underground excavations," International Journal of Rock Mechanics and Mining Sciences, vol. 44, no. 4, pp. 550-564, 2007.

[23] Q. Xu, Y. Li, J. Lu, and L. Zhang, "The use of surrounding rock loosening circle theory combined with elastic-plastic mechanics calculation method and depth learning in roadway support[J]," PLoS One, vol. 15, no. 7, Article ID e0234071, 2020 . 